\title{
AVALIAÇÃO DA QUALIDADE DO AÇAÍ (Euterpe oleracea, Mart.) COMERCIALIZADO NA CIDADE DE MACAPÁ - AP
}

\author{
CONSUELO L. SOUSA * \\ GILMA MARIA CUNHA MELO ** \\ SONIA CINTRA SOUZA ALMEIDA **
}

\begin{abstract}
Avaliou-se a qualidade microbiológica e microscópica de amostras de açaí, obtidas de julho a setembro de 1998 em batedeiras financiadas pelo Governo do Estado na cidade de Macapá - AP. Os resultados encontrados evidenciaram que $77,8 \%$ e $100 \%$ das amostras apresentaram coliformes fecais e bolores e leveduras, respectivamente, em níveis superiores aos estabelecidos na legislação vigente. Concluiu-se que as amostras de açaí comercializadas na cidade de Macapá apresentaram, sob o ponto de vista sanitário, condições higiênico-sanitárias insatisfatórias.
\end{abstract}

\section{INTRODUÇÃO}

O açaizeiro (Euterpe olerácea, Mart) é uma palmeira tropical, encontrada em estado silvestre principalmente na Amazônia Oriental, como parte da vegetação florística das matas de terra firme, várzea e igapó. Seus frutos são bastante procurados para a produção da bebida açaí (suco espesso de cor roxo violeta), utilizada na alimentação popular e na produção de picolés e sorvetes (5).

Nos hábitos alimentares do Amapaense, sem dúvida, o açaí é um dos principais constituintes, ficando seu consumo diário, somente na cidade de Macapá, entre 27.000 a 34.000 litros/dia. Além disso, verifica-se crescente expansão do mercado consumidor, principalmente no sul e sudeste do Brasil, por tratar-se de alimento com elevado teor energético.

O açaí se degrada em poucas horas e mesmo sob refrigeração, seu tempo máximo de conservação é de 12 horas (12). Segundo OLIVEIRA et al. (13) um dos fatores responsáveis pela sua perecebilidade é a grande carga microbiana presente no fruto.

* Profa. M.Sc. da Universidade Federal do Pará, Belém - PA.

** Especialista em Tecnologia dos Alimentos pelo Instituto de Pesquisas do Amapá (IEPA) -AP. 
Vários trabalhos relatando a contaminação microbiológica do açaí comercializado na cidade de Belém - PA, outra grande produtora e consumidora do mesmo, foram realizados $(4,6,13,18)$. Segundo ROGEZ et al. (15) o branqueamento do fruto, associado a outras etapas do processamento, diminui consideravelmente a carga microbiana do açaí.

ROGEZ et al. (14) explicaram a contaminação microbiológica do açaí pela conjunção dos seguintes fatores: o substrato é propício para o crescimento dos contaminantes (não ácido, não doce); a razão entre a superfície da fruta em contato com o ar e o peso da polpa é considerável (polpa de pequena espessura - $1 \mathrm{~mm}$ ); a palmeira de açaí cresce em meios tropicais muito úmidos e quentes, o que é propício ao crescimento de microrganismos e de insetos; a falta de cuidado durante a colheita e o transporte da fruta é a origem de contaminação suplementar pelo contato com superfícies contaminadas (solo, plásticos, recipientes, etc.).

Segundo BUXANT et al. (4) na entre safra a contaminação é maior, variando de $3,3 \times 10^{6}$ até $1,4 \times 10^{9} \mathrm{UFC} / \mathrm{g}$ de bactérias e de $2,4 \times 10^{4}$ até $8,3 \times 10^{6} \mathrm{UFC} / \mathrm{g}$ de bolores e leveduras. Na safra a contaminação de bactérias baixa em quase 100 vezes, mais ainda é alta, entre $1,3 \times 10^{6}$ e $3,3 \times 10^{7} \mathrm{UFC} / \mathrm{g}$, enquanto os bolores e leveduras permanecem na mesma faixa. A presença de coliformes fecais é demonstrada em $20 \%$ das amostras, tanto na safra como na entre safra, fato que compromete a qualidade do açaí segundo as normas do Ministério de Agricultura (2).

Sendo a boa qualidade dos alimentos essencial para a saúde pública, em 1997, foi realizado pelo LACEN - AP (Laboratório Central) em parceria com a Vigilância Sanitária uma avaliação microbiológica e físico-química do açaí e do fruto de açaí, comercializados na cidade de Macapá - AP. Os resultados mostraram que a qualidade do açaí estava em desacordo com os padrões estabelecidos pela Legislação da Secretária de Vigilância Sanitária do Ministério da Saúde (3). O Governo do Estado do Amapá de posse destes dados resolveu financiar 14 batedores de açaí do município de Macapá, pelo Programa de Desenvolvimento Sustentável do Estado. O objetivo era melhorar a qualidade do açaí comercializado, considerando que o produto movimenta aproximadamente $R \$ 20.500 .000,00$ (vinte milhões e quinhentos mil reais) entre o consumo do açaí e a extração de palmito. Em contrapartida as 14 batedoras deveriam construir locais de comercialização de alvenaria, com pisos e paredes lajotadas, providenciar gorro e avental para os manipuladores e submeter a água utilizada a algum tipo de tratamento.

O objetivo deste trabalho foi avaliar a qualidade microbiológica e microscópica do açaí (Euterpe oleracea, Mart.) e do fruto de açaí comercializados na cidade de Macapá - AP, depois do financiamento liberado pelo Governo do Estado. Os resultados encontrados foram 
comparados com os dados obtidos anteriormente pelo LACEN - AP em 1996.

\section{MATERIAL E MÉTODOS}

\subsection{AMOSTRAGEM}

No período de julho à setembro de 1998 foram obtidas, de batedeiras de açaí beneficiadas pelo Governo do Estado do Amapá, 09 amostras de açaí, 09 amostras do fruto e 09 amostras da água utilizada para preparo do açaí.

As amostras foram coletadas em frascos de vidro esterilizados e transportadas ao laboratório em caixa de isopor, contendo gelo reciclável e as análises iniciadas imediatamente.

\subsection{ANÁLISES MICROBIOLÓGICAS}

As amostras de açaí e do fruto foram analisadas quanto aos parâmetros exigidos pelo Ministério da Agricultura e do Abastecimento (Portaria $\mathrm{n}^{\circ} 78$ de 17 de março de 1998), ou seja, contagem de coliformes fecais, bolores e leveduras e Salmonella, além da contagem de coliformes totais e, Staphylococcus aureus, conforme metodologia descrita no Compendium of Methods for the Microbiological Examination of Foods (17). Para as amostras de água foi pesquisada a presença de coliformes totais, utilizando-se a técnica dos tubos múltiplos (NMP), recomendada pelo Standard Methods for the Examination of Water and Wastewater (1).

\subsubsection{Preparo das amostras}

Pesaram-se, assepticamente, duas porções de $25 \mathrm{~g}$ de cada amostra (açaí e fruto), as quais foram homogeneizadas com $225 \mathrm{~mL}$ de água peptonada $0,1 \%$, (diluição $10^{-1}$ ), sendo uma incubada a $35-37^{\circ} \mathrm{C}$ por 24 horas, para pré-enriquecimento de Salmonella. Da outra porção foram realizadas diluições decimais sucessivas, no mesmo diluente $\left(10^{-2}\right.$ a $\left.10^{-6}\right)$, para uso em outras determinações.

\subsubsection{Determinação do número mais provável (NMP) de coliformes totais e fecais (E.coli)}

Foi utilizada a técnica dos tubos múltiplos, com três séries de três tubos em cada diluição $\left(10^{-1}, 10^{-2}, 10^{-3}\right)$. Empregou-se como meio presuntivo o caldo lauril sulfato triptose com incubação a $35{ }^{\circ} \mathrm{C}$, durante 48 horas. No teste 
confirmatório foi utilizado o caldo lactose verde brilhante bile $2 \%$ para coliformes totais, com incubação a $35^{\circ} \mathrm{C}$ por $24-48$ horas e caldo EC para coliformes fecais com incubação a $44,5^{\circ} \mathrm{C}$, em banho-maria, por 24 horas. O NMP de coliformes totais e fecais foi determinado mediante tabela de Hoskins, a partir do número de tubos positivos nas diferentes diluições empregadas. Para fazer a identificação de $E$. coli os tubos positivos em caldo EC foram repicados para placas de Petri, contendo ágar eozina azul de metileno $(E M B)$ e incubadas a $35-37{ }^{\circ} \mathrm{C}$ por 24 horas. As colônias suspeitas (2 a $3 \mathrm{~mm}$ de diâmetro, com centro negro e bordas claras, e brilho metálico esverdeado) foram identificadas por testes bioquímicos (IMVIC).

\subsubsection{Pesquisa de Staphylococcus aureus}

Foi empregada a técnica da semeadura em superfície, utilizando-se o ágar Baird-Parker com incubação a $35{ }^{\circ} \mathrm{C}$ por $24-48$ horas. Colônias características de $S$. aureus foram numeradas e submetidas aos testes de produção de catalase, coagulase e termonuclease.

\subsubsection{Pesquisa de Bolores e Leveduras}

Empregou-se a técnica de semeadura em profundidade, utilizando-se ágar batata dextrose acidificado com ácido tartárico a $10 \%$ e incubação a $22-25^{\circ} \mathrm{C}$, por 5 dias.

\subsubsection{Pesquisa de Salmonella spp}

Foi empregada a técnica de pré-enriquecimento em água peptonada tamponada, com incubação a $35^{\circ} \mathrm{C}$, por 24 horas e enriquecimento em caldo selenito cistina e em caldo tetrationato, seguido de incubação a $35^{\circ} \mathrm{C}$ por 24 horas. Para o isolamento de colônias foi realizada semeadura em superfície em ágar ss e ágar hectoen, com incubação a $35^{\circ} \mathrm{C}$ por 24 horas. As colônias suspeitas foram confirmadas mediante testes bioquímicos (TSI, LIA Caldo Uréia, meio IAL, Caldo Malonato Fenil Alanina) e sorológicos (soro O e $\mathrm{H}$ polivalentes).

\subsection{ANÁLISE MICROSCÓPICA}

O exame microscópico do açaí e do fruto para a pesquisa de sujidades e parasitos (ovos, larvas e cistos) foi efetuado conforme técnicas descritas nas Normas Analíticas do Instituto Adolfo Lutz (8). 
RESULTADOS E DISCUSSÃO

Os resultados obtidos nas diferentes análises microbiológicas das amostras de açaí e do fruto de açaí estão apresentados nas Tabelas 1 e 2, respectivamente.

Constatou-se a ausência de Salmonella em todas as amostras analisadas que, segundo a Portaria $n^{\circ} 1$ da Secretaria Nacional de Vigilância Sanitária (3), deve estar ausente em $25 \mathrm{~g}$ de qualquer produto alimentício. Resultados idênticos foram obtidos por outros pesquisadores $(6,18)$ e pelo LACEN de Macapá - AP em 1996. OLIVEIRA et al. (13) em trabalho semelhante, realizado na cidade de Belém - PA, constataram a presença de Salmonella em 6,6\% das amostras de açaí analisadas.

A presença de S.aureus foi confirmada em $33,30 \%$ das amostras de açaí analisadas (Figura 1) e em 25\% das amostras do fruto (Figura 2), com contagem máxima de $2 \times 10^{3} \mathrm{UFC} / \mathrm{g}$ (Tabela 1 ) e de $8 \times 10^{2} \mathrm{UFC} / \mathrm{g}$ (Tabela 2), respectivamente. Números semelhantes foram obtidos por outros pesquisadores $(13,18)$. COROA et al. (6) obtiveram níveis mais elevados deste microrganismo $(42,5 \%)$ quando analisaram açaí produzido na ilha do Cumbú (PA). A presença de S.aureus acima de $10^{3} \mathrm{~g} / \mathrm{mL}$ classifica o produto como impróprio para o consumo, pois trata-se de bactéria patogênica produtora de enterotoxina, capaz de causar intoxicação alimentar $(9,10,16)$. É imprescindível que se tome o máximo de cuidado ao manusear produtos como o açaí, que muitas vezes servirá de almoço e jantar para inúmeras famílias. A contaminação pelo S.aureus no açaí pode ocorrer no próprio local de preparo, a partir do ar, poeira que se deposita nos objetos (bacias, canecos, baldes, concha) usados para o preparo do mesmo ou pela manipulação inadequada, já que o principal habitat desta espécie são as mucosas, o trato respiratório e a pele do homem $(9,16)$. De acordo com alguns autores $(7,10,11)$ é necessária população de S.aureus a partir de $10^{5} \mathrm{UFC} / \mathrm{g}$ para produção de enterotoxina, valor que não foi encontrado nas análises.

As Figuras 1 e 2 mostram a presença de bolores e leveduras em 100\% das amostras analisadas (açaí e fruto). Verifica-se pelas Tabelas 1 e 2 que todas as amostras apresentaram número de bolores e leveduras superiores a $10^{4} \mathrm{UFC} / \mathrm{g}$ de produto. Como a legislação vigente (2) recomenda para esta classe de microrganismo limite máximo de $10^{3}$ UFC/g, todas as amostras foram consideradas impróprias para o consumo. Resultados semelhantes foram relatados por outros pesquisadores quando avaliaram a qualidade de açaí em Belém - PA $(4,6,13,18)$ e pelo LACEN de Macapá - AP em 1996. Possivelmente estes resultados estão relacionados com vários fatores como por exemplo, umidade, temperatura e composição química do açaí, que provavelmente contribuem para estes valores elevados $(7,9,11)$. Segundo ROGEZ et al. (14) o açaí constitui-se em substrato excelente para crescimento de microrganismo, associado com a 
falta de cuidado durante a colheita e o transporte da fruta que entra em contato direto com terrenos úmidos, poeira do ar, utensílios e condições higiênicas insatisfatórias. Talvez por isto tenha sido isolado mais de 20 gêneros de bolores e fungos no açaí, sendo encontrado com maior freqüência a Debaryomyces hansenii.

TABELA 1 - PERFIL MICROBIOLÓGICO DO AÇAÍ COMERCIALIZADO EM MACAPÁ-AP PELAS BATEDEIRAS FINANCIADAS PELO GOVERNO DO ESTADO

\begin{tabular}{cccccc}
\hline Amostras & $\begin{array}{c}\text { Coliformes } \\
\text { Totais } \\
\text { NMP/g }\end{array}$ & $\begin{array}{c}\text { Coliformes } \\
\text { Fecais } \\
\text { NMP/g }\end{array}$ & $\begin{array}{c}\text { S. aureus } \\
\text { UFC/g }\end{array}$ & $\begin{array}{c}\text { Salmonella } \\
25 \mathrm{~g}\end{array}$ & $\begin{array}{c}\text { Bolores e } \\
\text { Leveduras } \\
\text { UFC/g }\end{array}$ \\
\hline $\mathrm{B}_{1}$ & $>1100$ & 1100 & Ausente & Ausente & $>10^{4}$ \\
$\mathrm{~B}_{2}$ & $>1100$ & 240 & $3 \times 10^{2}$ & Ausente & $>10^{4}$ \\
$\mathrm{~B}_{3}$ & $>1100$ & 1100 & $2 \times 10^{3}$ & Ausente & $>10^{5}$ \\
$\mathrm{~B}_{4}$ & $>1100$ & 150 & Ausente & Ausente & $>10^{5}$ \\
$\mathrm{~B}_{5}$ & $>1100$ & 1100 & Ausente & Ausente & $>10^{6}$ \\
$\mathrm{~B}_{6}$ & $>1100$ & 1100 & 1 ,4x10 & Ausente & $1,3 \times 10^{3}$ \\
$\mathrm{~B}_{7}$ & $>1100$ & $<3$ & Ausente & Ausente & $3 \times 10^{5}$ \\
$\mathrm{~B}_{8}$ & $>1100$ & $<3$ & Ausente & Ausente & $9 \times 10^{4}$ \\
$\mathrm{~B}_{9}$ & $>1100$ & $<3$ & Ausente & Ausente & $1,7 \times 10^{7}$ \\
\hline
\end{tabular}

\section{TABELA 2 - PERFIL MICROBIOLÓGICO DO FRUTO DE AÇAÍ COMERCIALIZADO EM MACAPÁ-AP PELAS BATEDEIRAS FINANCIADAS PELO GOVERNO DO ESTADO}

\begin{tabular}{cccccc}
\hline Amostras & $\begin{array}{c}\text { Coliformes } \\
\text { Totais } \\
\text { NMP/g }\end{array}$ & $\begin{array}{c}\text { Coliformes } \\
\text { Fecais } \\
\text { NMP/g }\end{array}$ & $\begin{array}{c}\text { S. aureus } \\
\text { UFC/g }\end{array}$ & $\begin{array}{c}\text { Salmonella } \\
25 \mathrm{~g}\end{array}$ & $\begin{array}{c}\text { Bolores e } \\
\text { Leveduras } \\
\text { UFC/g }\end{array}$ \\
\hline $\mathrm{C}_{1}$ & $>1100$ & - & - & Ausente & $>10^{4}$ \\
$\mathrm{C}_{2}$ & $>1100$ & 1100 & $2,1 \times 10^{2}$ & Ausente & $>10^{4}$ \\
$\mathrm{C}_{3}$ & $>1100$ & 460 & $8,0 \times 10^{2}$ & Ausente & $>10^{5}$ \\
$\mathrm{C}_{4}$ & $>1100$ & 240 & Ausente & Ausente & $>10^{5}$ \\
$\mathrm{C}_{5}$ & $>1100$ & 1100 & Ausente & Ausente & $>10^{6}$ \\
$\mathrm{C}_{6}$ & $>1100$ & $<3$ & Ausente & Ausente & $6,3 \times 10^{6}$ \\
$\mathrm{C}_{7}$ & $>1100$ & $<3$ & Ausente & Ausente & $>10^{4}$ \\
$\mathrm{C}_{8}$ & $>1100$ & $<3$ & Ausente & Ausente & $>10^{5}$ \\
$\mathrm{C}_{9}$ & $>1100$ & $<3$ & Ausente & Ausente & $1,2 \times 10^{7}$ \\
\hline
\end{tabular}

- não analisada

Os resultados presentes nas Tabelas 1,2 e 3 e nas Figuras 1 e 2 demostram que, $100 \%$ das amostras de açaí e do fruto e $33,3 \%$ da água utilizada para produzir o açaí estavam contaminados por coliformes totais, e a maioria das amostras, com contagem elevada, indicando condições higiênicas precárias. Estes resultados são concordantes com os obtidos por outros pesquisadores $(13,18)$ e pelo LACEN de Macapá - AP. A E. coli foi isolada em $77,8 \%$ das amostras de açaí pesquisadas, assim como o 
LACEN encontrou contaminação por este microrganismo em 20 das 24 amostras analisadas. Tal fato demonstra que as condições higiênicosanitárias nos estabelecimentos não mudaram muito de 1996 para 1998.

\section{FIGURA 1 - RESULTADOS PERCENTUAIS DAS ANÁLISES MICROBIOLÓGICAS DO AÇAÍ}

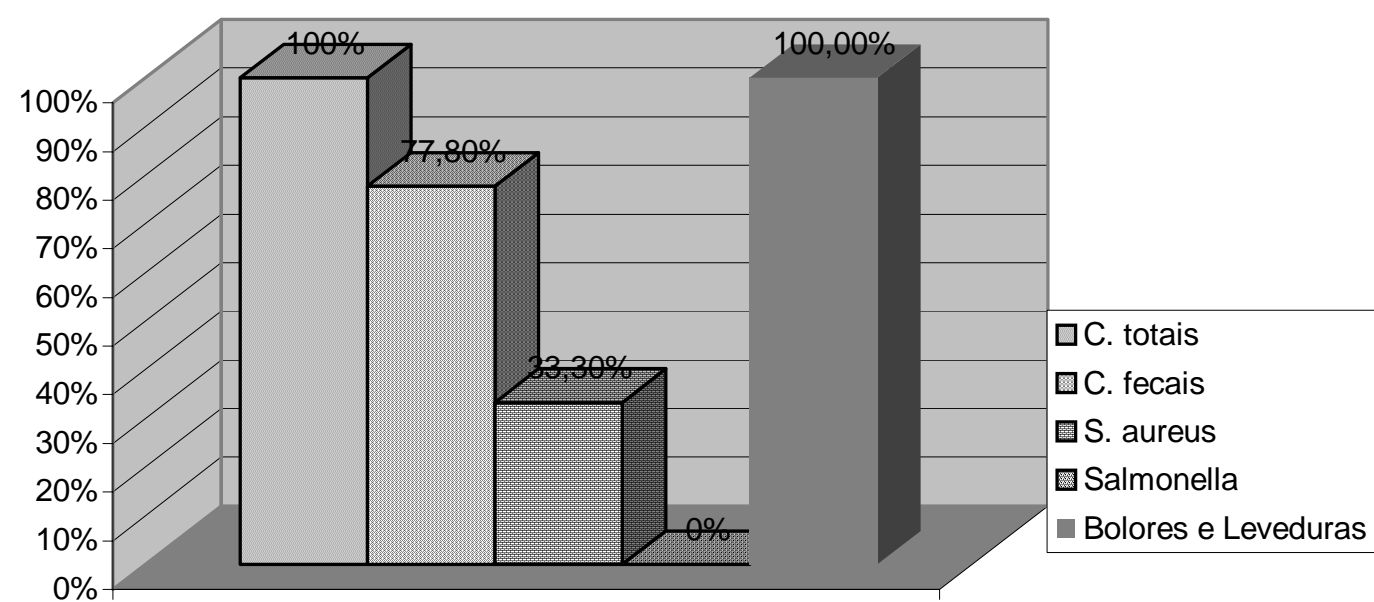

1

Determinações

\section{FIGURA 2 - RESULTADOS PERCENTUAIS DAS ANÁLISES MICROBIOLÓGICAS DO FRUTO DE AÇAí}

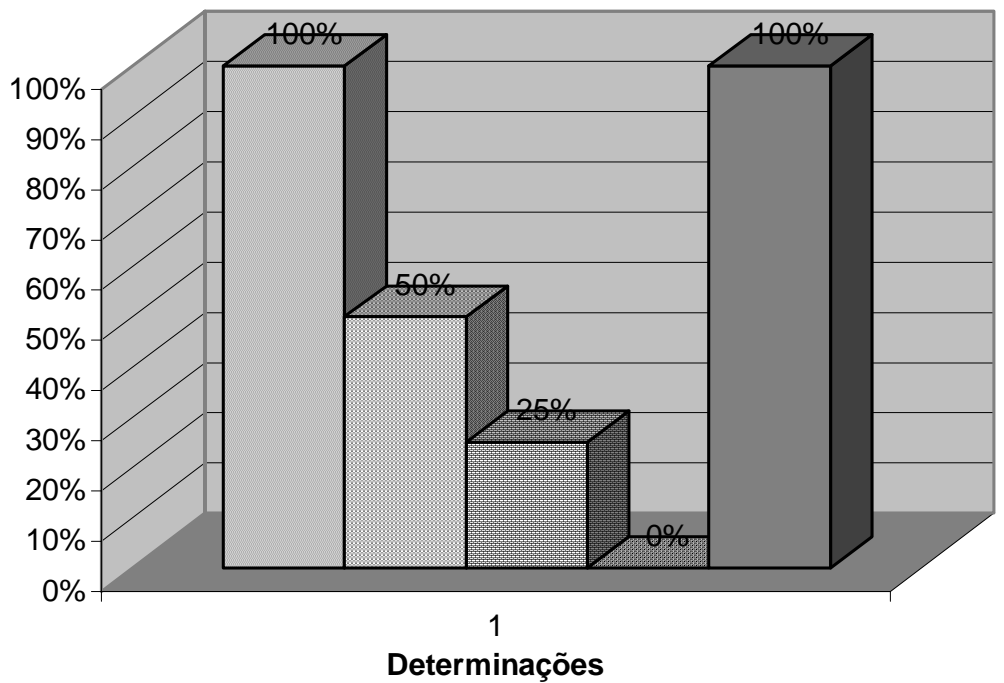

Determinações 


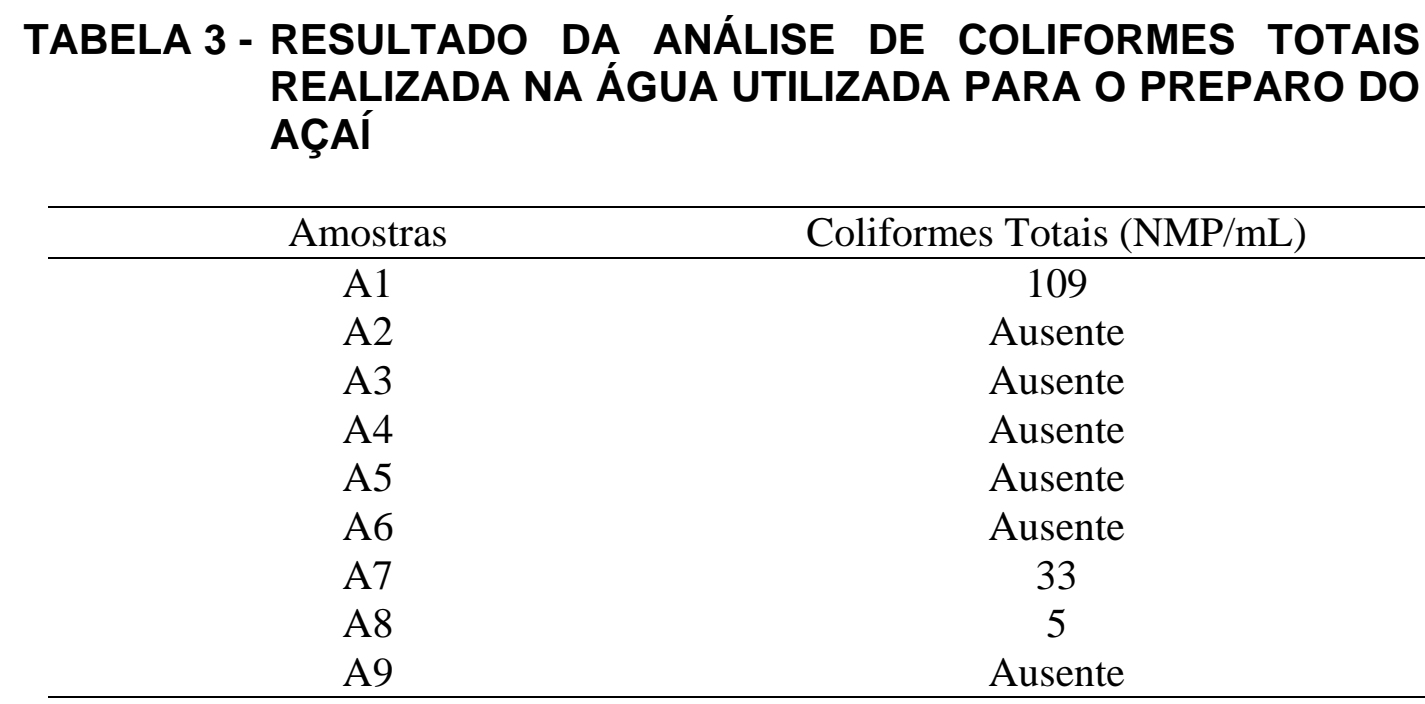

Não foi verificada a presença de sujidade e parasitas em nenhuma das 18 amostras analisadas (açaí e fruto).

\title{
4 CONCLUSÃO
}

De acordo com os resultados obtidos concluiu-se que, sob o ponto de vista sanitário, a maioria das amostras de açaí comercializadas na cidade de Macapá - AP apresentaram condições higiênico-sanitárias insatisfatórias. Recomenda-se portanto, a aplicação mais efetiva dos princípios de higiene e sanitização na produção das mesmas, visando oferecer produtos com qualidade microbiológica aceitável.

\begin{abstract}
In the period of July through September 1998, it was evaluated the microbiological and microscopic quality of samples of Euterpe oleracea Mart., obtained from local merchants sponsored by the State Government, in the city of Macapá, Brazil. The results showed that $77.8 \%$ and $100 \%$ of the samples presented fecal coliforms, and moulds and yeast, respectively, in levels above the limits established by Federal Legislation. It was concluded that the fruit samples commercialized in the city of Macapá presented, under the sanitary point of view, unsatisfactory hygienic-sanitary conditions.
\end{abstract}

\section{REFERÊNCIAS BIBLIOGRÁFICAS}

1 AMERICAN PUBLIC HEALTH ASSOCIATION. Standard methods for the examination of water and wastewater. 19.ed.

Washington, 1995. $1100 \mathrm{p}$. 
BRASIL. Ministério da Agricultura e Abastecimento. Portaria n. 78 de 17 de março de 1998. Aprova os padrões de identidade e qualidade para polpas de frutas de açaí, de acerola, de graviola, de cupuaçu e de cacau. Diário Oficial [da República Federativa do Brasil], Brasília, n. 52, seção 1, p. 39, 18 de março de 1998.

BRASIL. Ministério da Saúde. Divisão de Vigilância Sanitária de Alimentos-DINAL. Portaria n. 001 de 28 de janeiro de 1987. Aprova padrões microbiológicos para os produtos destinados ao consumo. Diário Oficial [da República Federativa do Brasil], Brasília, Seção 1, p. 2197, 12 de fevereiro de 1987.

BUXANT, R., ROGEZ, H., AQUINO, A.R., SOUZA, J.N. DE, SOUSA, C.L. Qualidade microbiológica do suco de açaí (Euterpe oleracea Mart.) comercializado na cidade de Belém - Pará. In: CONGRESSO BRASILEIRO DE MICROBIOLOGIA, 19, 1997, Rio de Janeiro. Resumos... Rio de Janeiro : SBM, 1997. p. 276. amazônico. Belém : FCAP, 1972. (Boletim Técnico, n. 5). de, JARDIM, M.A.G. Análise microbiológica do suco de açaí produzido em uma comunidade ribeirinha do estuário amazônico. Boletim do Museu Paraense Emílio Goeldi, v. 11, n. 2, 1995. (Série Botânica)

FRAZIER, W.C., WESTHOFF, D.C. Microbiologia de los alimentos. Zaragoza : Acribia, 1985.

INSTITUTO ADOLFO LUTZ. Normas analíticas do Instituto Adolfo Lutz: metódos químicos e físicos para análise do alimento. 2.ed. São Paulo, 1985.

9 INTERNATIONAL COMMISSION ON MICROBIOLOGICAL SPECIFICATIONS FOR FOODS. Microrganisms in foods. 1. significance and methods of enumeration. 2.ed. Toronto, 1978. v.1. Nostrand Reinhold, 1978.

11 FRANCO, B.D.G.M., LANDGRAF, M. Microbiologia dos alimentos. São Paulo : Atheneu, 1996.

12 NASCIMENTO, M. J. Mercado e comercialização de frutos de açaí. Belém : UFPA, 1992. (Relatório de Pesquisa, T. 3). 
13 OLIVEIRA, M. de L.S., SOUSA, C.L., OLIVEIRA, R.A. Qualidade microbiológica da bebida açaí (Euterpe oleracea Mart.) comercializada na cidade de Belém. In: ENCONTRO DE PROFISSIONAIS DE QUÍMICA DA AMAZÔNIA, 6., 1988, Manaus. Anais... Belém : CRQ, 1988. p. 189-195.

14 ROGEZ, H., PASCAL, S., BUXANT, R., LOPES, S.Q., COLSONCORBISIER, A.M. Identificação dos principais fungos e leveduras presentes na polpa do açaí (Euterpe oleracea Mart.). In: CONGRESSO BRASILEIRO DE MICROBIOLOGIA, 19, 1997, Rio de Janeiro. Resumos... Rio de Janeiro : SBM, 1997. p. 269.

15 ROGEZ, H., SOUZA, J.N.S. de, NASCIMENTO, M. de Q., BUXANT, R., PASCAL, S. Branqueamento dos frutos de açaí (Euterpe oleracea Mart) para a diminuição da carga microbiana do suco. Anais da Assoc. Bras. Quím., v. 45, n. 4, p. 177-184, 1996.

ROITMAM, I., TRAVASSOS, L.R., AZEVEDO, J.L. Tratado de microbiologia. São Paulo : Manolo, 1988. v. 1.

17 VANDERZANT, C., SPLITTSTOESSER,D.F. Compendium of methods for microbiological examination of foods. 3.ed. Washington, DC : American Public Health Association, 1992.

VELOSO, S.S.C., SANTOS, M.L.S. Aspectos microbiológicos da bebida açaí (Euterpe oleracea, Mat.) consumida na cidade de Belém. Belém, 1994. Trabalho de Conclusão do Curso de Química Industrial da Universidade Federal do Pará, 1994. 